\title{
Oppositional Teaching and Learning Based Optimization of Economical Load Dispatch Problem with Valve Point Loading Effect
}

\author{
Dsnm Rao ${ }^{1 *}$, Chunchu Pushpa Latha ${ }^{2}$, Narukullapati Bharath Kumar ${ }^{3}$, Perumallu Mahalingam Venkatesh ${ }^{3}$ \\ ${ }^{1}$ Department of Electrical \& Electronics Engineering, Gokaraju Rangaraju Institute of Engineering and Technology, Hyderabad \\ 522213, Telangana, India \\ ${ }^{2}$ Department of Electrical and Electronics Engineering, G V R \& S College of Engineering \& Technology, Guntur 522013, \\ Andhra Pradesh, India \\ ${ }^{3}$ Department of Electrical \& Electronics Engineering, VFSTR University, Vadlamudi 522213, A.P, India
}

Corresponding Author Email: 2015rsee003@nitjsr.ac.in

https://doi.org/10.18280/jesa.520514

Received: 11 June 2019

Accepted: 13 August 2019

\section{Keywords:}

economic load dispatch (ELD), cost function, oppositional teaching and learning based optimization (OTLBO), valve point loading effect

\begin{abstract}
Economic load dispatch (ELD) problems are traditionally solved by convex optimization techniques. However, these techniques are no longer effective if the ELD problem has a nonconvex cost function. This paper aims to find a suitable meta-heuristic method to solve the ELD problem with non-convex cost function. The ELD of generators in a power system with valve point loading effect was taken as the research problem. Then, several meta-heuristic optimization techniques were compared in their abilities to find the global optimal solution, namely, the lambda iteration method, the teaching and learning based optimization (TLBO) and the oppositional teaching and learning based optimization (OTLBO). The optimization techniques were thoroughly compared through demonstrations on 6,10 , and 14 units test systems. The results show that the OTLBO outperformed the other algorithms in terms of the global optimal solution. Thus, our research confirms the feasibility and effectiveness of the OTLBO for ELD problems with valve point loading effect.
\end{abstract}

\section{INTRODUCTION}

Nowadays, the electric energy market became more and more competitive so that to survive this current situation, optimal power generation is required to minimize the total power generation cost. ELD determines minimum cost operation of network with dispatching the generation sources to meet the load demand. ELD main objective is to minimize the total generation cost and satisfying the several constraints. Nowadays, generator scheduling is a big problem for power engineers. Since from the past few decades, number of techniques are practiced for economic load dispatch problems. The ELD tells that optimal generator scheduling of loads so that supplying power must be equal to power demanding and power losses as a decreasing fuel cost [1]. Actually the power generation cost is very high. In India the major power is generated from thermal power plants where the running cost is too high. So it is necessary to minimize the power generation cost as well as transmission losses for ELD problems [2-3]. Many researchers implemented to number of algorithms to solution of economic load dispatch problems.

Simulated \& evolutionary programming algorithms which are integrated based and developed for solving the problems of ELD [4]. Barisal et al. has presented a novel optimization method which contains bacterial foraging technique used to solve the ELD Problems [5]. Issarachai et al. implemented an effective novel technique which is based on ant colony method for optimizing ELD problems based on non-smooth cost functions [6]. Lin et al. [7] developed novel quantum genetic algorithm which is used to solving the ELD problems that having wind power. Seeker optimization technique is used for solving ELD problems which attains human capabilities like understanding and searching [8]. Artificial immune technique which is clonal selection based is applicable to solve the ELD Problems with valve loading effects [9]. Devendra Sharma et al. implemented a hybrid PSO which is based on multi-agent technique to solve ELD problems [10] ELD problems include transmission loses, cubic fuel and quadratic fuel cost functions are solved by equal embedded algorithm [11]. MohammadiIvatloo et al. [12] have been implemented to solve the dynamic economic load dispatch problems by using optimality condition decomposition technique.

A novel technique and coding is implemented for power system economical load dispatch problems using effortless hybrid method (EHM) [13]. Subrahmanyam et al. [11] implemented a novel technique which is used to power system economical load dispatch problems with cubic fuel cost function and transmission loses through hybrid partcile swarm optimization technique which is multo agent based. This technique resolves the PSO problems which are randomness, variables tuning and unique solution [14]. Both convex and nonconvex economic dispatch problems of thermal plants are solved by aBBOmDE techinc [15]. A novel technic is proposed to solve the economic dispatch problems using reinforcement learning method [16].

Ongsakul et al. [17] proposed a novel technique to solve the nonconvex economic problems using on Hopfield neural networks technique which hybrid-based method. Further, augmented Lagrange Hopfield network was introduced to solve ELD problems with prohibited zones. Basically this method is based on quadratic programming and piecewise quadratic cost function [18]. However these methods are 
suffering from the excessive iterations and resulting in large competitions. Singh et al. have been formulated and modelled both stochastic and deterministic technique which is improved particle swarm optimization have been developed to solve the economical dispatch problems with environmental effect [19]. This paper explores the new meta-heuristic algorithm i.e. oppositional teaching and learning based optimization technique to solve the ELD problems with valve point loading effect. Previously many mathematical programming methods are developed for solving ELD problems in order to get convergence solution. Linear programming techniques are effective but it will applicable only for piecewise linear cost functions. So nonlinear programming approaches have to be implement for solution of non-linear cost functions. NR based methods cannot solve the equality constraints problems [20].

This paper tells the solution of ELD problem with valve point loading effect by OTLBO algorithm with consideration of transmission losses. In this paper, OTLBO algorithm is implemented for different test systems i.e. 6, 10 and 14 unit test system and also compared with TLBO algorithm. Finally, OTLBO algorithm gives high quality solution for global minimization.

Section 2 describing about problem formulation related ELD Problem

Section 3 discusses the simulation results about proposed optimization technique and also compared with existing techniques and Section 4 explains conclusions from the present work gestions for future investigations.

\section{PROBLEM FORMULATION}

Load dispatch solutions defines reducing the fuel cost, real power balancing and satisfying the demand of active power. The ELD problem is represented by Savsani et al. [21]

$$
F C\left(P_{i}\right)=\sum_{i=1}^{N} F_{i}\left(P_{i}\right)
$$

Here $F C\left(P_{i}\right)=$ overall fuel cost,

$P_{i}=$ Power generation of $i^{\text {th }}$ thermal generating unit

The fuel cost is quadratic function so it is,

$$
F_{i}\left(P_{i}\right)=a_{i} P_{g i}^{2}+b_{i} P_{g i}+c_{i}
$$

Subjected to

$$
\begin{gathered}
\sum_{i=1}^{n} P_{i}=P_{D}+P_{L} \\
P_{i, \text { min }} \leq P_{i} \leq P_{i, \text { max }}
\end{gathered}
$$

\subsection{Economic dispatch problem with valve-point loading effect}

Here valve point effect means sum of quadratic function function plus sinusoidal cost function which is represented by Pal et al. [22].

$$
F_{i}\left(P_{i}\right)=a_{i}+b_{i} P_{i}+c_{i} P_{i}^{2}+\left|e_{i}^{*} \sin \left(f_{i}^{*}\left(P_{i}^{\mathrm{min}}-P_{i}\right)\right)\right|
$$

Here $e_{i}$ and $f_{i}$ are generating units reflecting coefficients. The line losses are represented by

$$
P_{L}=\sum_{i=1}^{n} \sum_{j=1}^{n} P_{i} B_{i j} P_{j}+\sum_{i=1}^{n} P_{i} B_{0 i}+B_{00}
$$

Here $\mathrm{B}_{\mathrm{ij}}, \mathrm{B}_{0 \mathrm{i}}$ and $\mathrm{B}_{00}$ are coefficients of line loss.

\section{SIMULATION RESULTS \& DISCUSSION}

The OTLBO algorithm effectiveness and feasibility is tested on standard test systems like $6,10,14$ and results are also compared with TLBO algorithm as well as Lambda iteration method.

\subsection{The proposed algorithm is implemented as per the flow chart}

Step 1: Define the system data includes generators fuel cost coefficients, generation limit and demand power.

Step 2: now teacher phase starts and generators mean value will be determined. Obtain the all population size cost value.

Step 3: select the fittest population size and teacher is assigned based on minimum cost.

Step 4: now learner phase starts and improvement of generation due to interaction with different learners.

Step 5: Stop the iteration process if termination criteria satisfies. The number of iterations are represented in this paper is termination criteria. Finally, the global best fitness and corresponding generation is obtained.

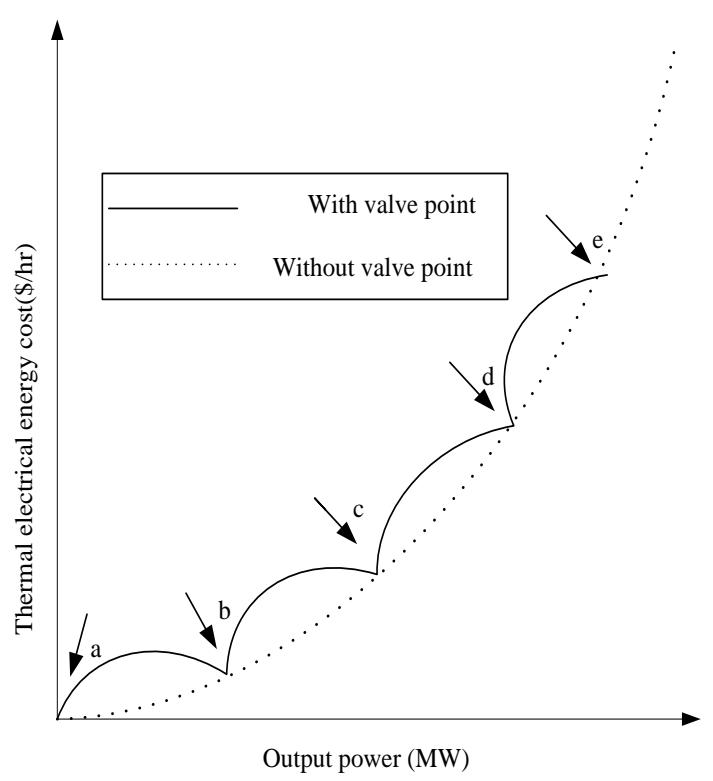

Figure 1. Input and output curve with and without valvepoint loading effect- $\mathrm{a}, \mathrm{b}, \mathrm{c}, \mathrm{d}$ and $\mathrm{e}$ are valve points

Figure 1 shows the operating cost characteristics of thermal station generators with and without valve-points loading Effect.

Figure 2 illustrates the step by step procedure of TLBO algorithm to optimize the ELD problem in the power system network. 


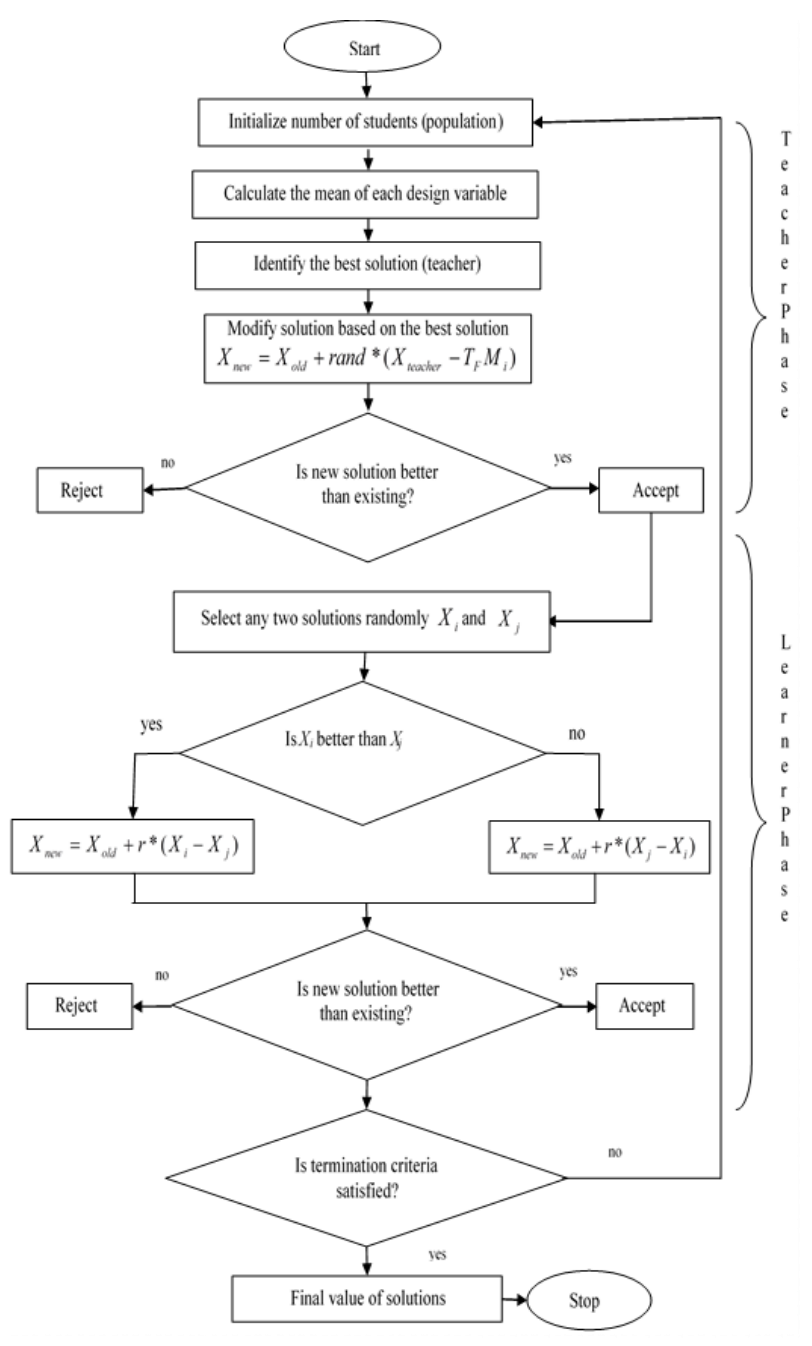

Figure 2. TLBO algorithm flow chart

\subsection{Test system1: Six unit test system}

This case, a non-convex cost function based 6 thermal units are considered. The proposed method effectiveness is tested on two different load demands 800 and $1263 \mathrm{MW}$ that can be meet by 6 thermal units. The test system data taken from Ref. [23]. In this case population size is assumed as 60 . The TLBO \& OTLBO load dispatch results are formulated in Table 1. In this case, 25 independent trails have been made with 200 iterations per trail. Based on the performance, three different methods results are compared shown in below Table $1 \& 2$.

From the Table 1, at load demand of $800 \mathrm{MW}$, the obtained minimum cost by Lambda iteration is $9528.7222 \$ / \mathrm{h}$ with the power loss of $5.9642 \mathrm{MW}$. The obtained minimum cost by OTLBO method is $9528.7969 \$ / \mathrm{h}$ with the power loss of $5.9597 \mathrm{MW}$. The cost obtained by TLBO is $9528.8844 \$ / \mathrm{h}$ with power loss of 6.0179 MW. From the records, its clearly shows that the obtained minimum cost by all the methods is almost same as the global solution at the load demand of $800 \mathrm{MW}$.

From Table 2, now the power demand of 1263MW, the obtained minimum cost by Lambda iteration method and OTLBO is $15449.8995 \$ / \mathrm{h}$ with the power loss of $12.9582 \mathrm{MW}$. The minimum cost obtained by TLBO is $15450.6753 \$ / \mathrm{h}$ with the power loss of $12.8536 \mathrm{MW}$. The cost obtained by Lambda iteration method and OTLBO is same as the global solution.

Figure 3 shows the comparison of convergence characteristics at different populations for different methods. As shown fig $\mathrm{x}$ axis represents iterations and $\mathrm{y}$ axis represents minimum cost in $\$ / \mathrm{hr}$.

\subsection{Test system 2: 10-unit system}

This case, a non-convex cost function based 10 thermal units are considered. The performance of the proposed methods was demonstrated at two different load demands and that load demands meet by ten thermal units are 1500 and 2000MW. The test data taken from [24]. Here 100 population size is taken. The dispatch results of 10-unit system using the proposed methods are given in Table 2. For this test system, trails of 25 independent are made with 300 iterations/trail. Based on data obtained, the comparisons of six thermal units test by different methods are presented in Table $3 \& 4$
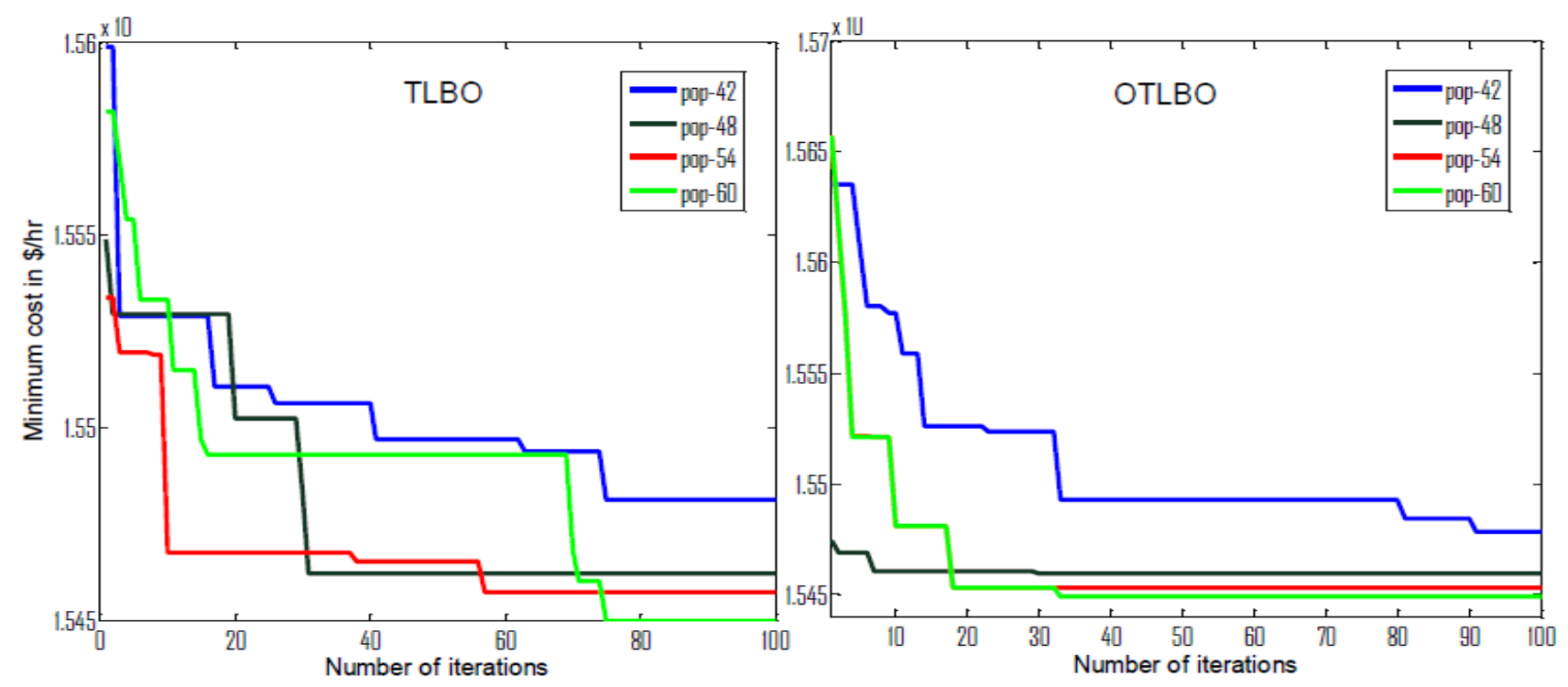

Figure 3. Comparison of convergence characteristics for different populations

From the Table 3, at load demand of $1500 \mathrm{MW}$ the obtained minimum cost by Lambda iteration technique and TLBO is $81130.0325 \$ / \mathrm{h}$ with the power loss of $49.0223 \mathrm{MW}$. The obtained minimum cost by OTLBO technique is $81129.7603 \$ / \mathrm{h}$ with the power loss of $49.007 \mathrm{MW}$. From the above records it says clearly that the obtained minimum cost 
by the OTLBO is the global solution at the load demand of $1500 \mathrm{MW}$.

Table 1. Comparisonal results for 6-unit system with load demand of $800 \mathrm{MW}$

\begin{tabular}{cccc}
\hline \multirow{2}{*}{ Unit } & & $\mathbf{P}_{\mathbf{D}}=\mathbf{8 0 0} \mathbf{M W}$ & \\
\cline { 3 - 3 } & Lambda & TLBO & OTLBO \\
\hline $\mathbf{1}$ & 342.2421 & 343.4325 & 339.6431 \\
$\mathbf{2}$ & 95.4819 & 96.5919 & 96.5813 \\
$\mathbf{3}$ & 181.9937 & 183.1756 & 183.2407 \\
$\mathbf{4}$ & 53.6758 & 50 & 53.9589 \\
$\mathbf{5}$ & 82.5707 & 82.8179 & 82.5354 \\
$\mathbf{6}$ & 50.0000 & 50 & 50 \\
$\begin{array}{c}\text { Generation } \\
\text { cost in \$/hr }\end{array}$ & 9528.7222 & 9528.8844 & 9528.7969 \\
$\begin{array}{c}\text { Power loss in } \\
\text { MW }\end{array}$ & 5.9642 & 6.0179 & 5.9597 \\
\hline
\end{tabular}

Table 2. Comparisonal results for 6-unit system with load demand of $1263 \mathrm{MW}$

\begin{tabular}{cccc}
\hline \multirow{2}{*}{ Unit } & & $\mathbf{P}_{\mathbf{D}=1263 ~ M W}$ & \\
\cline { 3 - 3 } & Lambda & TLBO & OTLBO \\
\hline $\mathbf{1}$ & 447.5038 & 444.4068 & 447.5038 \\
$\mathbf{2}$ & 173.3182 & 170.8177 & 173.3182 \\
$\mathbf{3}$ & 263.4628 & 263.9355 & 263.4628 \\
$\mathbf{4}$ & 139.0653 & 146.5230 & 139.0652 \\
$\mathbf{5}$ & 165.4734 & 166.4267 & 165.4733 \\
$\mathbf{6}$ & 87.1347 & 83.7436 & 87.1347 \\
$\begin{array}{c}\text { Generation } \\
\text { cost in \$/hr }\end{array}$ & 15449.8995 & 15450.6753 & 15449.8995 \\
$\begin{array}{c}\text { Power loss in } \\
\text { MW }\end{array}$ & 12.9582 & 12.8536 & 12.9582 \\
\hline
\end{tabular}

Table 3. Comparisonal results for 10-unit system with demand of $1500 \mathrm{MW}$

\begin{tabular}{|c|c|c|c|}
\hline \multirow{2}{*}{ Unit } & \multicolumn{3}{|c|}{$P_{D}=1500 M W$} \\
\hline & Lambda & TLBO & OTLBO \\
\hline 1 & 43.5706 & 43.5706 & 45.6086 \\
\hline 2 & 60.8157 & 60.8157 & 61.7683 \\
\hline 3 & 72.1301 & 72.1301 & 67.6629 \\
\hline 4 & 60.3987 & 60.3987 & 55.5074 \\
\hline 5 & 51.3367 & 51.3367 & 51.4848 \\
\hline 6 & 71.3367 & 71.3367 & 71.4848 \\
\hline 7 & 207.1676 & 207.1676 & 209.5246 \\
\hline 8 & 222.2243 & 222.2243 & 232.5880 \\
\hline 9 & 372.1789 & 372.1789 & 375.2049 \\
\hline 10 & 387.8631 & 387.8631 & 378.1727 \\
\hline $\begin{array}{l}\text { Generation } \\
\text { cost in } \$ / h r\end{array}$ & 81130.0325 & 81130.0325 & 81129.7603 \\
\hline $\begin{array}{c}\text { Power loss in } \\
\text { MW }\end{array}$ & 49.0223 & 49.0223 & 49.0070 \\
\hline
\end{tabular}

From Table 4, now power demand of 2000MW the obtained minimum cost by Lambda iteration method is $111261.5057 \$ / \mathrm{h}$ with the power loss of $87.0403 \mathrm{MW}$. The obtained minimum cost by OTLBO method is $11261.5051 \$ / \mathrm{h}$ with the power loss of $87.0403 \mathrm{MW}$. The TLBO obtained cost is $111289.9482 \$ / \mathrm{h}$ with power loss of 87.1252 . Therefore, the cost obtained by Lambda iteration method and OTLBO is almost same but the cost obtained by OTLBO method is global minimum.

Figure 4 shows the graphical representation of comparison convergence characteristics of obtained minimum cost for 20runs at load demand $2000 \mathrm{MW}$. As shown in fig the cost obtained by Lambda iteration method is constant for all runs while the other methods are varying.
Table 4. Comparisonal results for 10-unit system with demand of $1500 \mathrm{MW}$

\begin{tabular}{cccc}
\hline \multirow{2}{*}{ Unit } & & \multicolumn{2}{c}{$\mathbf{P}_{\mathbf{D}=\mathbf{2 0 0 0} \mathbf{M W}}$} \\
\cline { 3 - 3 } $\mathbf{1}$ & Lambda & TLBO & OTLBO \\
\cline { 2 - 3 } $\mathbf{2}$ & 55.0000 & 55.0000 & 55.0000 \\
$\mathbf{3}$ & 107.0000 & 80.0000 & 80.0000 \\
$\mathbf{4}$ & 99.90004 & 120.0000 & 107.0151 \\
$\mathbf{5}$ & 81.9005 & 95.5547 & 99.9007 \\
$\mathbf{6}$ & 83.2229 & 77.8408 & 81.9024 \\
$\mathbf{7}$ & 300.0000 & 300.0000 & 83.2221 \\
$\mathbf{8}$ & 340.0000 & 340.0000 & 340.0000 \\
$\mathbf{9}$ & 470.0000 & 470.0000 & 470.0000 \\
$\mathbf{1 0}$ & 470.0000 & 470.0000 & 470.0000 \\
Generation cost & 111261.5057 & 111289.9482 & 111261.5051 \\
in \$/hr & & & \\
Power loss in & 87.0403 & 87.1252 & 87.0403 \\
MW & & & \\
\hline
\end{tabular}

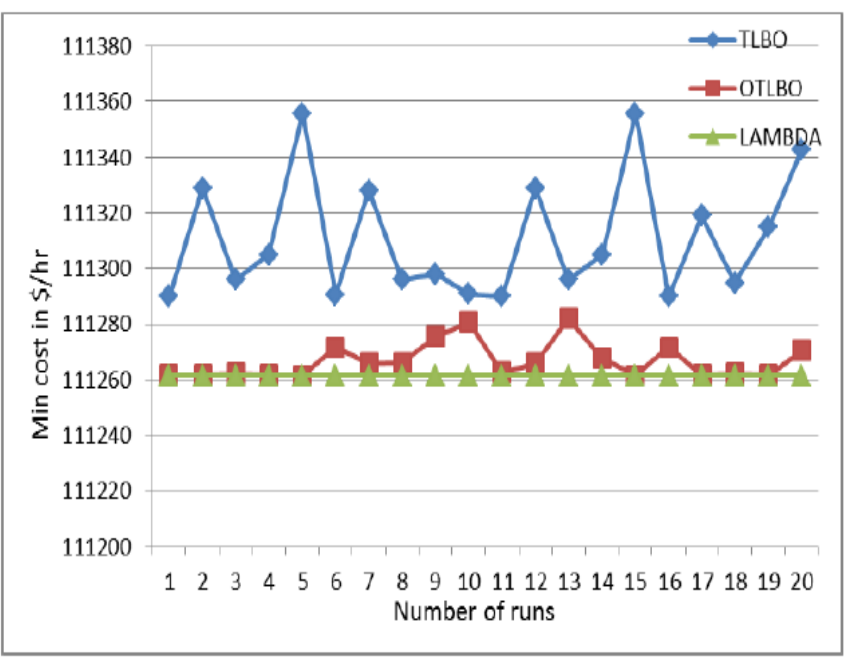

Figure 4. Comparison of convergence characteristics of obtained minimum cost for 20runs

\subsection{Test system 3: 14-unit system}

This case, a non-convex cost function based 14 thermal units are considered. The performance of the proposed methods is demonstrated at two different load demands and that load demands meet by 14 thermal units are 1500 and 2000MW. The data taken from Ref. [25]. Here population is 140. The dispatch results of 14-unit system using the proposed methods are given in Tables $5 \& 6$. For this test system, 500 iterations per trail are made with 25 independent trails. From the data, six thermal units' comparisons shown by different methods are presented in Tables $5 \& 6$.

From the Table 5, power demand of $1500 \mathrm{MW}$, obtained minimum cost by Lambda iteration method is $6612.5868 \$ / \mathrm{h}$ with the power loss of $17.9213 \mathrm{MW}$. The obtained minimum cost by OTLBO technique is $6612.5089 \$ / \mathrm{h}$ with the power loss of 18.1087 MW. TLBO produced the cost of 6612.5120 $\$ / \mathrm{h}$ with power loss of $18.1655 \mathrm{MW}$. It has been showed that the minimum cost obtained by all the methods is almost same but the cost obtained by OTLBO is the global solution at the load demand of 1500MW.

From Table 6 , now at the power demand of $2000 \mathrm{MW}$, the obtained cost from all the methods is almost same but the cost obtained by OTLBO method is global minimum and it is $8895.4566 \$ / \mathrm{h}$ with power loss of $30.7713 \mathrm{MW}$. 
Table 5. Comparisonal results for 14-unit system with demand of $1500 \mathrm{MW}$

\begin{tabular}{cccc}
\hline \multirow{2}{*}{ Unit } & & $\mathbf{P}_{\mathbf{D}}=\mathbf{1 5 0 0} \mathbf{M W}$ & \\
\cline { 2 - 3 } $\mathbf{1}$ & Lambda & $\mathbf{T L B O}$ & OTLBO \\
\cline { 2 - 3 } $\mathbf{2}$ & 221.3101 & 220.1858 & 218.5729 \\
$\mathbf{3}$ & 189.0354 & 192.2743 & 190.7673 \\
$\mathbf{4}$ & 50.5688 & 49.1485 & 53.1257 \\
$\mathbf{5}$ & 88.2294 & 86.0241 & 88.1582 \\
$\mathbf{6}$ & 150.0000 & 150.0258 & 150.0026 \\
$\mathbf{7}$ & 135.0000 & 135.0258 & 135.0026 \\
$\mathbf{8}$ & 135.0000 & 135.0258 & 135.0026 \\
$\mathbf{9}$ & 60.0000 & 60.0258 & 60.0026 \\
$\mathbf{1 0}$ & 139.6414 & 139.3569 & 136.2976 \\
$\mathbf{1 1}$ & 127.1018 & 130.8644 & 132.3087 \\
$\mathbf{1 2}$ & 79.9875 & 80.0000 & 80.0000 \\
$\mathbf{1 3}$ & 79.9875 & 80.0000 & 80.0000 \\
$\mathbf{1 4}$ & 15.0593 & 45.1827 & 43.8651 \\
Generation & 6612.5868 & 6612.5120 & 6612.5089 \\
cost in \$/hr & & & \\
Power loss & 17.9213 & 18.1655 & 18.1087 \\
in MW & & & \\
\hline
\end{tabular}

Table 6. Comparisonal results for 14-unit system with demand of $2000 \mathrm{MW}$

\begin{tabular}{|c|c|c|c|}
\hline \multirow{2}{*}{ Unit } & \multicolumn{3}{|c|}{$P_{D}=2000 \mathrm{MW}$} \\
\hline & Lambda & TLBO & OTLBO \\
\hline 1 & 310.6826 & 308.1352 & 312.1435 \\
\hline 2 & 269.8385 & 276.6890 & 271.6552 \\
\hline$\overline{3}$ & 120.5517 & 117.5742 & 116.8470 \\
\hline 4 & 129.9988 & 130.0000 & 130.0000 \\
\hline 5 & 192.9272 & 192.3146 & 193.8548 \\
\hline 6 & 163.3757 & 162.2258 & 165.2621 \\
\hline 7 & 136.9125 & 136.0410 & 136.1677 \\
\hline 8 & 84.6855 & 86.0736 & 82.8410 \\
\hline 9 & 162.0000 & 162.0000 & 162.0000 \\
\hline 10 & 159.9811 & 160.0000 & 160.0000 \\
\hline 11 & 80.0000 & 80.0000 & 80.0000 \\
\hline 12 & 80.0000 & 80.0000 & 80.0000 \\
\hline 13 & 85.0000 & 85.0000 & 85.0000 \\
\hline 14 & 55.0000 & 55.0000 & 55.0000 \\
\hline $\begin{array}{l}\text { Generation } \\
\text { cost in } \$ / \mathrm{hr}\end{array}$ & 8895.6328 & 8895.5806 & 8895.4566 \\
\hline $\begin{array}{l}\text { Power loss } \\
\text { in MW }\end{array}$ & 30.9535 & 31.0534 & 30.7713 \\
\hline
\end{tabular}

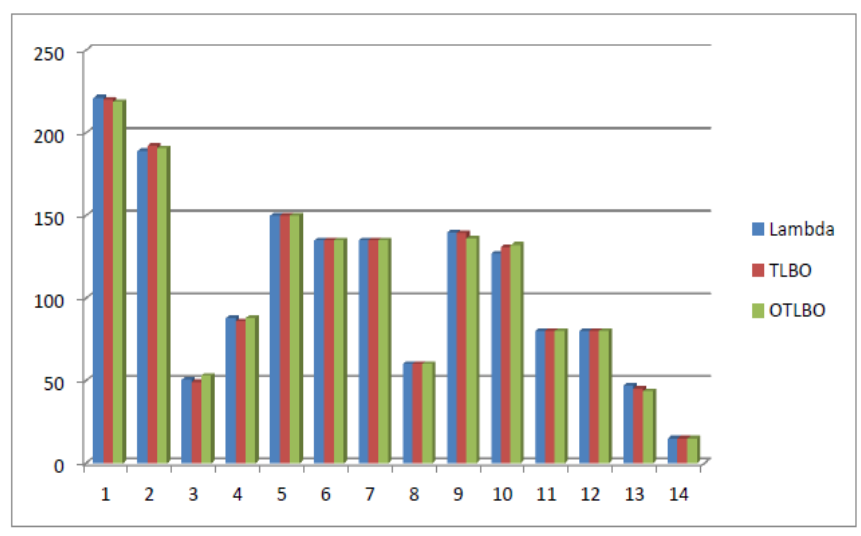

Figure 5. Distribution of generation conceded by ten generators at $P_{D}=1500 \mathrm{MW}$

Figure 4 shows how the generation shared by fourteen generators with respect to their minimum and maximum limits which means it satisfies the inequality constraint. From the equality constraint, the fourteen generators generation should meet to given load demand.

\section{CONCLUSION}

In this paper, standard ELD problem can be solved in different cases with different methods. In first case ELD problem is represented with non-convex cost-function, already present there in network. The algorithms TLBO \& OTLBO are successfully used to minimize the ELD problem considering 6 , 10 and 14-unit test systems and also distinguished with lambda technique to test the performance of the proposed algorithm. The proposed algorithm OTLBO found better solution for all test systems than TLBO. This investigation results certainly says that the proposed method can be utilized as effective optimization providing better satisfactory solutions for ELD problems. The paper established algorithms for the ELD problem to have the optimal solution for valve point loading effect only. However i strongly recommend that, in few cases there is still a need to investigate more avenues such as prohibited operating zones, ramp rate limits and multiple fuel selections for each unit. Here only thermal generating units have been considered. The ELD of hydro units can be applied by engaging these novel techniques. I also recommend that the new techniques have been used for combined hydrothermal economic load dispatch for future scope.

\section{REFERENCES}

[1] Wollenberg, B.F., Wood, A.J., Sheble, G.B. (2013). Power Generation, Operation, and Control. $3^{\text {rd }}$ Edition. Wiley Publication.

[2] Nasiri-Rad, H., Amjady, N. (2010). Solution of nonconvex and nonsmooth economic dispatch by a new Adaptive Real Coded Genetic Algorithm. Expert Systems with Applications, 37(7): 5239-5245. https://doi.org/10.1016/j.eswa.2009.12.084

[3] Rao, R.V., Patel, V. (2013). An improved teachinglearning-based optimization algorithm for solving unconstrained optimization problems. Scientia Iranica D, 20(3):

710-720. https://doi.org/10.1016/j.scient.2012.12.005

[4] Rajan, C.C.A. (2010). A solution to the economic dispatch using EP based SA algorithm on large scale power system. International Journal of Electrical Power \& Energy Systems, 32(6): 583-591. https://doi.org/10.1016/j.ijepes.2009.11.014

[5] Barisal, A.K., Hota, P.K., Chakrabarti, R. (2010). Economic emission load dispatch through fuzzy based bacterial foraging algorithm. International Journal of Electrical Power \& Energy Systems, 32(7): 794-803. https://doi.org/10.1016/j.ijepes.2010.01.016

[6] Ngamroo, I., Pothiya, S., Kongprawechnon, W. (2010). Ant colony optimisation foreconomic dispatch problem with non-smooth cost functions. International Journal of Electrical Power \& Energy Systems, 32(5): 478-487. https://doi.org/10.1016/j.ijepes.2009.09.016

[7] Lin, W.M., Lee, J.C., Liao, G.C., Tsao, T.P. (2011). Quantum genetic algorithm for dynamic economic dispatch with valve-point effects and including wind power system. International Journal of Electrical Power 
\& Energy Systems, 33(2): 189-197. https://doi.org/10.1016/j.ijepes.2010.08.014

[8] Mukherjee, V., Shaw, B., Ghoshal, S.P. (2011). Seeker optimization algorithm: application to the solution of economic load dispatch problems. IET Generation, Transmission \& Distribution, 5(1): 81-91. https://doi.org/10.1049/iet-gtd.2010.0405

[9] Simon, S.P., Hemamalini, S. (2011). Dynamic economic dispatch using artificial immune system for units with valve-point effect. International Journal of Electrical Power \& Energy Systems, 33(4): 868-874. https://doi.org/10.1016/j.ijepes.2010.12.017

[10] Sharma, D., Kumar, R., Sadu, A. (2011). A hybrid multiagent based particle swarm optimization algorithm for economic power dispatch. International Journal of Electrical Power \& Energy Systems, 33(1): 115-123. https://doi.org/10.1016/j.ijepes.2010.06.021

[11] Subrahmanyam, N., Chandram, K., Sydulu, M. (2011). Equal embedded algorithm for economic load dispatch problem with transmission losses. International Journal of Electrical Power \& Energy Systems, 33(3): 500-507. https://doi.org/10.1016/j.ijepes.2010.12.002

[12] Mohammadi-Ivatloo, B., Rabiee, A., Moradi-Dalvand, M. (2014). Fast dynamic economic power dispatch problems solution via optimality condition decomposition. IEEE Transactions on Power Systems, 29(2): https://doi.org/10.1109/TPWRS.2013.2288028

[13] Rashidi-Nejad, M., Pourakbari-Kasmaei, M. (2011). An effortless hybrid method to solve economic load dispatch problem in power systems. Energy Conversion and Management, $\quad 52(8-9)$ : $\quad$ 2854-2860. https://doi.org/10.1016/j.enconman.2011.02.018

[14] Vijaya Muthu, P.S., Thanushkodi, K. (2011). An evolutionary programming based efficient particle swarm optimization for economic dispatch problem with valve-point loading. European Journal of Scientific Research, 52(3): 385-397. http://hdl.handle.net/10603/24146

[15] Panigrahi, B.K., Lohokare, M.R., Pattnaik, S.S. (2012). Neighborhood search-driven accelerated biogeographybased optimization for optimal load dispatch. IEEE Transactions on Systems, Man, and Cybernetics, Part C (Applications and Reviews), 42(5): 641-652. https://doi.org/10.1109/TSMCC.2012.2190401

[16] Imthias Ahamed, T.P., Jasmin, E.A., Jagathy Raj, V.P. (2011). Reinforcement learning approaches to economic dispatch problem. International Journal of Electrical Power \& Energy Systems, 33(4): 836-845. https://doi.org/10.1016/j.ijepes.2010.12.008

[17] Ongsakul, W., Dieu, V.N., Polprasert, J. (2013). The augmented Lagrange Hopfield network for economic dispatch with multiple fuel options. Mathematical and Computer Modelling, 57(1-2): 30-39. https://doi.org/10.1016/j.mcm.2011.03.041

[18] Schegner, P., Dieu, V.N. (2013). Augmented Lagrange Hopfield network initialized by quadratic programming for economic dispatch with piecewise quadratic cost functions and prohibited zones. Applied Soft Computing, 13(1): 292-301. https://doi.org/10.1016/j.asoc.2012.08.026

[19] Singh, C., Wang, L. (2008). Stochastic economic emission load dispatch through a modified particle swarm optimization algorithm. Electric Power Systems Research, 78(8): 1466-1476. https://doi.org/10.1016/j.epsr.2008.01.012

[20] Lin, W.M., Gow, H.J., Tsai, M.T. (2011). A novel stochastic search method for the solution of economic dispatch problems with non-convex fuel cost functions. International Journal of Electrical Power \& Energy Systems, 33(4): 1070-1076. https://doi.org/10.1016/j.ijepes.2011.01.026

[21] Savsani, V.J., Rao, R.V., Vakharia, D.P. (2011). Teaching-learning-based optimization: A novel method for constrained mechanical design optimization problems. Computer-Aided Design, 43(3): 303-315. https://doi.org/10.1016/j.cad.2010.12.015

[22] Pal, T., Roy, P.K., Pradhan, M. (2016). Grey wolf optimization applied to economic load dispatch problems. International Journal of Electrical Power \& Energy Systems, 83: 325-334. https://doi.org/10.1016/j.ijepes.2016.04.034

[23] Simon, P., Hemamalini, S. (2008). Emission constrained economic dispatch with valve point effect using particle swarm optimization. IEEE International conference (TENCON 2008), 1-6. https://doi.org/10.1109/TENCON.2008.4766473

[24] Basu, M. (2011). Economic environmental dispatch using multi-objective differential evolution. Applied Soft Computing, $11(2)$ : 2845-2853. https://doi.org/10.1016/j.asoc.2010.11.014

[25] Chakraborty, N., Mandal, K.K. (2008). Effect of control parameters on differential evolution based combined economic emission dispatch with valve-point loading and transmission loss. International Journal of Emerging Electric Power Systems, 9(4): 1-20. https://doi.org/10.2202/1553-779X.1918 